\title{
Design of Integral Variable Structure Controller in Speed Tracking of Wind Driven Generator
}

\author{
Linlin Wang ${ }^{1}$ and Lixin Pan ${ }^{2}{ }^{2}$ \\ ${ }^{1}$ College of Information, Inner Mongolia University of Technology, Hohhot 010080, China \\ ${ }^{2}$ Beijing Institute of Control Engineering, China Academy of Space Technology, Beijing 100094, China \\ Correspondence should be addressed to Lixin Pan; panlixin1@126.com
}

Received 3 November 2018; Revised 9 March 2019; Accepted 18 March 2019; Published 19 May 2019

Academic Editor: Francisco R. Villatoro

Copyright (c) 2019 Linlin Wang and Lixin Pan. This is an open access article distributed under the Creative Commons Attribution License, which permits unrestricted use, distribution, and reproduction in any medium, provided the original work is properly cited.

In order to obtain the optimum power factor through maintaining the ratio of blade tip speed to wind speed, a new method for controller design of wind driven generator speed tracking is proposed basing on variable structure control theory. Integral variable of generator speed is introduced into the system equation. Switching surface of variable structure controller is founded with the error of generator speed. Adaptive estimation for wind disturbance and uncertain parameters of system dynamics model is adopted to derive control algorithm for rotation torque in the process of generator speed tracking. Simulation results show that speed tracking precision of wind driven generator is improved by integral variable structure controller. The method proposed in this article is effective and feasible.

\section{Introduction}

Wind energy is favored around the world due to its green and renewable characteristics. At present, wind power technology is maturely developed and widely used commercially. Wind driven generator is the core of wind power system. How to control the generator efficiently is very important to the whole wind power system.

The main goal of wind power system control is to improve the power quality, reduce the power production cost, and achieve the maximum power output under safe and reliable system operation conditions. Classical maximum power tracking control strategy includes the maximum power point tracking control based on wind turbine power curve, the maximum power point tracking control based on optimal tip speed ratio, and the maximum power point tracking control based on optimal torque [1]. At present, domestic and foreign scholars achieve a lot of research findings on the basis of the above classical methods. In Reference [2], the maximum power point tracking control strategy for doublyfed induction generator is proposed, which is based on direct power control. This control strategy has the advantages of fast dynamics response and strong robustness due to the adoption of direct power control method based on sliding mode control. In Reference [3], the maximum power point tracking control method based on optimal tip speed ratio is proposed, where a doubly-fed induction generator is regarded as the research object. The influence of reactive power, power grid voltage, and wind speed on generator output power can be suppressed through this method. In Reference [4], the optimal torque compensator based on gradient estimates is designed for solving the problem of lower efficiency and long transient time due to large moment of inertia for wind turbine in the maximum power point tracking control based on optimal torque. Given value of electromagnetic torque is compensated by the optimal torque compensator; then the influence of large moment of inertia on rotation speed variation of wind turbine is reduced.

Because power tracking strategy based on optimal tip speed ratio has good accuracy and response speed, in addition, some uncertain parameters and disturbances exist in the wind power system, but variable structure control strategy has the advantage of overcoming parameter uncertainty and external disturbance [5]; therefore, variable structure control method is adopted in this paper, which is on basis of power tracking strategy based on optimal tip speed ratio 


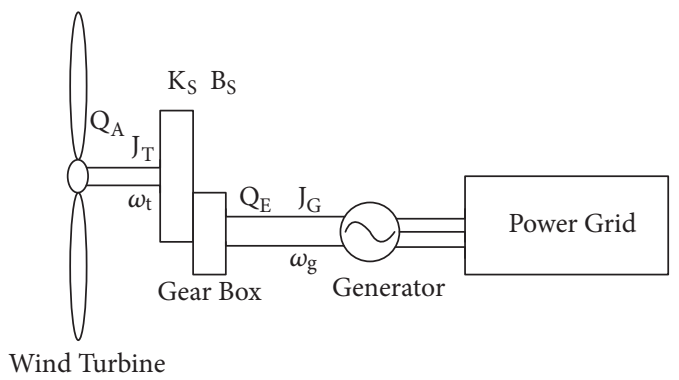

FIGURE 1: System of wind driven generator.

and has strong robustness. Because the wind power system is disturbed by external gust wind (wind speed varies in a small range and can be approximately regarded as constant disturbance), steady deviation occurs in generator speed control and cannot be eliminated by ordinary variable structure controller. In this paper, integral variable structure controller is adopted to realize generator speed tracking and adaptive estimation is applied to optimize the selection of variable structure controller parameters. As a result, the effect of speed tracking is further improved.

\section{Design of Speed Tracking Controller for Wind Driven Generator}

2.1. Dynamics Model of Wind Power System. Wind power system is mainly composed of wind turbine, gear box, and generator, as shown in Figure 1. The wind turbine with rotation speed $\omega_{t}$ produces torque $\mathrm{Q}_{\mathrm{A}}$, which is transmitted through the gear box, and then the generator can obtain rotational torque $\mathrm{Q}_{\mathrm{E}}$ and work at speed $\omega_{\mathrm{g}}$.

Dynamics equation of the whole system can be expressed as

$$
\begin{aligned}
\mathrm{Q}_{\mathrm{A}}-\mathrm{Q} & =\mathrm{J}_{\mathrm{T}} \dot{\omega}_{\mathrm{t}} \\
\frac{\mathrm{Q}}{\mathrm{n}}-\mathrm{Q}_{\mathrm{E}} & =\mathrm{J}_{\mathrm{G}} \dot{\omega}_{\mathrm{g}} \\
\mathrm{Q} & =\mathrm{K}_{\mathrm{S}} \int_{0}^{\mathrm{t}}\left(\omega_{\mathrm{t}}-\omega_{\mathrm{g}}\right) \mathrm{dt}+\mathrm{B}_{\mathrm{S}}\left(\omega_{\mathrm{t}}-\omega_{\mathrm{g}}\right)
\end{aligned}
$$

where $\mathrm{J}_{\mathrm{T}}$ is the inertia coefficient of wind turbine, $\mathrm{J}_{\mathrm{G}}$ is the inertia coefficient of generator, $K_{S}$ is the elastic coefficient, and $\mathrm{B}_{\mathrm{S}}$ is the damping coefficient. The energy captured by wind turbine from the wind can be expressed as

$$
\mathrm{P}(\mathrm{w})=\frac{1}{2} \pi \rho \mathrm{R}^{2} \mathrm{C}_{\mathrm{P}}(\lambda) \mathrm{w}^{3}
$$

where $\rho$ is air density, $\mathrm{R}$ is wind turbine radius, $\mathrm{w}$ is wind speed in upstream, $C_{p}(\lambda)$ is wind energy utilization coefficient, and $\lambda$ is blade tip speed ratio, which is defined as

$$
\lambda=\frac{\mathrm{R} \omega_{\mathrm{t}}}{\mathrm{w}}
$$

If blade tip speed ratio $\lambda$ equals optimal tip speed ratio $\lambda_{\text {opt }}$, the operation of the wind turbine can be maintained with the maximum wind energy utilization coefficient $\mathrm{C}_{\mathrm{Pmax}}$. Therefore, when wind speed $\mathrm{w}$ varies, the maximum wind energy utilization coefficient $\mathrm{C}_{\mathrm{Pmax}}$ can be obtained through adjusting rotation speed of generator $\omega_{\mathrm{g}}$ to keep the ratio between blade tip speed $\omega_{\mathrm{t}}$ and wind speed $\mathrm{w}$ at $\lambda_{\mathrm{opt}} / \mathrm{R}$. This is the main goal for wind power system to realize speed control of generator.

The wind turbine torque, which is expressed as equation (6), can be derived from equation (4) and equation (5).

$$
\mathrm{Q}_{\mathrm{A}}=\frac{1}{2} \rho \mathrm{ARC}_{\mathrm{q}}(\lambda) \mathrm{w}^{2}
$$

where $C_{q}(\lambda)$ is the torque coefficient of wind turbine and can be expressed as a nonlinear function of $\lambda$.

$$
\mathrm{C}_{\mathrm{P}}(\lambda)=\lambda \mathrm{C}_{\mathrm{q}}(\lambda)
$$

Equation (8) can be obtained through linearization of $\mathrm{Q}_{\mathrm{A}}$ at the optimal working point

$$
\Delta \mathrm{Q}_{\mathrm{A}}=\alpha \Delta \mathrm{W}+\gamma \Delta \omega_{\mathrm{t}}
$$

where

$$
\begin{aligned}
& \alpha=\frac{\partial \mathrm{Q}_{\mathrm{A}}}{\partial \mathrm{w}} \mathrm{I}_{\mathrm{opt}}=\mathrm{Cw}_{\mathrm{opt}}\left(2 \mathrm{C}_{\mathrm{q}(\mathrm{opt})}-\lambda_{\mathrm{opt}} \mathrm{C}_{\mathrm{q}}^{\prime} \mathrm{I}_{\mathrm{opt}}\right) \\
& \gamma=\left.\frac{\partial \mathrm{Q}_{\mathrm{A}}}{\partial \omega_{\mathrm{t}}}\right|_{\mathrm{opt}}=\left.\mathrm{CR} \omega_{\mathrm{t}(\mathrm{opt})} \mathrm{C}_{\mathrm{q}}^{\prime}\right|_{\text {opt }}
\end{aligned}
$$

Then the system dynamics equation can be further described as

$$
\begin{aligned}
& \dot{\mathrm{x}}=\left[\begin{array}{ccc}
\frac{\gamma-\mathrm{B}_{\mathrm{S}}}{\mathrm{J}_{\mathrm{T}}}+\Delta \mathrm{a} & \frac{\mathrm{B}_{\mathrm{S}}}{\mathrm{J}_{\mathrm{T}}} & -\frac{1}{\mathrm{~J}_{\mathrm{T}}} \\
\frac{\mathrm{B}_{\mathrm{S}}}{\mathrm{J}_{\mathrm{G}}} & -\frac{\mathrm{B}_{\mathrm{S}}}{\mathrm{J}_{\mathrm{G}}} & \frac{1}{\mathrm{~J}_{\mathrm{G}}} \\
\mathrm{K}_{\mathrm{S}}+\Delta \mathrm{b} & -\mathrm{K}_{\mathrm{S}} & 0
\end{array}\right] \mathrm{x}+\left[\begin{array}{c}
0 \\
-\frac{1}{\mathrm{~J}_{\mathrm{G}}} \\
0
\end{array}\right] \mathrm{u}+\mathrm{w}_{\mathrm{I}} \\
& \mathrm{y}=\left[\begin{array}{lll}
0 & 1 & 0
\end{array}\right] \mathrm{x}
\end{aligned}
$$

where $^{T}=\left[\begin{array}{lll}\omega_{\mathrm{t}} & \omega_{\mathrm{g}} & \mathrm{Q}_{\mathrm{S}}\end{array}\right], \mathrm{Q}_{\mathrm{S}}=\mathrm{K}_{\mathrm{S}} \int_{0}^{\mathrm{t}}\left(\omega_{\mathrm{t}}-\omega_{\mathrm{g}}\right) \mathrm{dt}, \mathrm{u}=\mathrm{Q}_{\mathrm{E}}, \Delta \mathrm{a}$ and $\Delta \mathrm{b}$ are uncertain parameters, $\chi$ is a positive constant, and $\mathrm{w}_{\mathrm{I}}$ denotes the gust wind disturbance which can be expressed as $\mathrm{w}_{\mathrm{I}}^{\mathrm{T}}=\left[\begin{array}{lll}\chi \cdot \mathrm{w} & 0 & 0\end{array}\right]$.

2.2. Design of Speed Tracking Controller for Wind Driven Generator. According to equation (11), the dynamics equations of wind turbine and generator are, respectively, expressed as

$$
\begin{aligned}
& \dot{\omega}_{\mathrm{t}}=\left(\frac{\gamma-\mathrm{B}_{\mathrm{S}}}{\mathrm{J}_{\mathrm{T}}}+\Delta \mathrm{a}\right) \omega_{\mathrm{t}}+\frac{\mathrm{B}_{\mathrm{S}}}{\mathrm{J}_{\mathrm{T}}} \omega_{\mathrm{g}}-\frac{1}{\mathrm{~J}_{\mathrm{T}}} \mathrm{Q}_{\mathrm{S}}+\chi \cdot \mathrm{w} \\
& \dot{\omega}_{\mathrm{g}}=\frac{\mathrm{B}_{\mathrm{S}}}{\mathrm{J}_{\mathrm{G}}} \omega_{\mathrm{t}}-\frac{\mathrm{B}_{\mathrm{S}}}{\mathrm{J}_{\mathrm{G}}} \omega_{\mathrm{g}}+\frac{1}{\mathrm{~J}_{\mathrm{G}}} \mathrm{Q}_{\mathrm{S}}-\frac{1}{\mathrm{~J}_{\mathrm{G}}} \mathrm{Q}_{\mathrm{E}}
\end{aligned}
$$

Both sides of equation (14) are differentiated, and then

$$
\ddot{\omega}_{\mathrm{g}}=\frac{\mathrm{B}_{\mathrm{S}}}{\mathrm{J}_{\mathrm{G}}} \dot{\omega}_{\mathrm{t}}-\frac{\mathrm{B}_{\mathrm{S}}}{\mathrm{J}_{\mathrm{G}}} \dot{\omega}_{\mathrm{g}}+\frac{1}{\mathrm{~J}_{\mathrm{G}}} \dot{\mathrm{Q}}_{\mathrm{S}}-\frac{1}{\mathrm{~J}_{\mathrm{G}}} \dot{\mathrm{Q}}_{\mathrm{E}}
$$


According to equation (11), equation (16) can be obtained:

$$
\dot{\mathrm{Q}}_{\mathrm{S}}=\left(\mathrm{K}_{\mathrm{S}}+\Delta \mathrm{b}\right) \omega_{\mathrm{t}}-\mathrm{K}_{\mathrm{S}} \omega_{\mathrm{g}}
$$

Equation (13) and equation (16) are substituted into equation (15); then

$$
\begin{aligned}
\ddot{\omega}_{\mathrm{g}} & =\frac{1}{\mathrm{~J}_{\mathrm{T}} \mathrm{J}_{\mathrm{G}}}\left\{-\mathrm{B}_{\mathrm{S}} \mathrm{J}_{\mathrm{T}} \dot{\omega}_{\mathrm{g}}+\left(\mathrm{B}_{\mathrm{S}}^{2}-\mathrm{J}_{\mathrm{T}} \mathrm{K}_{\mathrm{S}}\right) \omega_{\mathrm{g}}-\mathrm{J}_{\mathrm{T}} \dot{\mathrm{Q}}_{\mathrm{E}}\right. \\
& +\mathrm{B}_{\mathrm{S}} \mathrm{J}_{\mathrm{T}} \chi \mathrm{w} \\
& +\left[\mathrm{B}_{\mathrm{S}}\left(\gamma-\mathrm{B}_{\mathrm{S}}\right)+\mathrm{B}_{\mathrm{S}} \mathrm{J}_{\mathrm{T}} \Delta \mathrm{a}+\mathrm{J}_{\mathrm{T}}\left(\mathrm{K}_{\mathrm{S}}+\Delta \mathrm{b}\right)\right] \omega_{\mathrm{t}} \\
& \left.-\mathrm{B}_{\mathrm{S}} \mathrm{K}_{\mathrm{S}} \int_{0}^{\mathrm{t}}\left(\omega_{\mathrm{t}}-\omega_{\mathrm{g}}\right) \mathrm{dt}\right\}=\frac{1}{\mathrm{~J}_{\mathrm{T}} \mathrm{J}_{\mathrm{G}}}\left\{-\mathrm{B}_{\mathrm{S}} \mathrm{J}_{\mathrm{T}} \dot{\omega}_{\mathrm{g}}\right. \\
& \left.+\left(\mathrm{B}_{\mathrm{S}}^{2}-\mathrm{J}_{\mathrm{T}} \mathrm{K}_{\mathrm{S}}\right) \omega_{\mathrm{g}}-\mathrm{J}_{\mathrm{T}} \dot{\mathrm{Q}}_{\mathrm{E}}-\mathrm{J}_{\mathrm{T}} \mathrm{Q}_{\mathrm{D}}\right\}
\end{aligned}
$$

where

$$
\begin{aligned}
\mathrm{Q}_{\mathrm{D}}= & -\mathrm{B}_{\mathrm{S}} \chi \mathrm{w} \\
& -\left[\frac{\mathrm{B}_{\mathrm{S}}\left(\gamma-\mathrm{B}_{\mathrm{S}}\right)}{\mathrm{J}_{\mathrm{T}}}+\mathrm{B}_{\mathrm{S}} \Delta \mathrm{a}+\left(\mathrm{K}_{\mathrm{S}}+\Delta \mathrm{b}\right)\right] \omega_{\mathrm{t}} \\
& +\frac{\mathrm{B}_{\mathrm{S}} \mathrm{K}_{\mathrm{S}}}{\mathrm{J}_{\mathrm{T}}} \int_{0}^{\mathrm{t}}\left(\omega_{\mathrm{t}}-\omega_{\mathrm{g}}\right) \mathrm{dt}
\end{aligned}
$$

If $\mathrm{X}^{\prime}=\left[\begin{array}{lll}\omega_{\mathrm{gI}} & \omega_{\mathrm{g}} & \dot{\omega}_{\mathrm{g}}\end{array}\right]^{\mathrm{T}}$ and $\omega_{\mathrm{gI}}$ is defined as the integral variable of generator speed, which satisfies

$$
\dot{\omega}_{\mathrm{gI}}=\omega_{\mathrm{g}}
$$

then the extended system equation can be obtained from equation (17) to equation (19) and expressed as

$$
\dot{\mathrm{X}}^{\prime}=\mathrm{A}^{\prime} \mathrm{X}^{\prime}+\mathrm{B}^{\prime}\left(\mathrm{U}+\mathrm{Q}_{\mathrm{D}}\right)
$$

where

$$
\begin{aligned}
\mathrm{A}^{\prime} & =\left[\begin{array}{ccc}
0 & 1 & 0 \\
0 & 0 & 1 \\
0 & \frac{\mathrm{B}_{\mathrm{S}}^{2}-\mathrm{J}_{\mathrm{T}} \mathrm{K}_{\mathrm{S}}}{\mathrm{J}_{\mathrm{T}} \mathrm{J}_{\mathrm{G}}} & -\frac{\mathrm{B}_{\mathrm{S}}}{\mathrm{J}_{\mathrm{G}}}
\end{array}\right] \\
\mathrm{B}^{\prime} & =\left[\begin{array}{lll}
0 & 0 & -\frac{1}{\mathrm{~J}_{\mathrm{G}}}
\end{array}\right]^{\mathrm{T}} \\
\mathrm{U} & =\dot{\mathrm{Q}}_{\mathrm{E}}
\end{aligned}
$$

If system state error is defined as

$$
\mathrm{X}_{\mathrm{e}}=\mathrm{X}^{\prime}-\mathrm{X}_{\mathrm{R}}
$$

where $\mathrm{X}_{\mathrm{R}}=\left[\begin{array}{lll}\omega_{\mathrm{gI} 0} & \omega_{\mathrm{g} 0} & \dot{\omega}_{\mathrm{g} 0}\end{array}\right]^{\mathrm{T}}$ and $\mathrm{X}_{\mathrm{R}}$ is the given speed signal instruction of generator, switching function can be designed as

$$
\mathrm{S}=\mathrm{CX}_{\mathrm{e}}
$$

where $\mathrm{C}$ is $1 \times 3$ dimension matrix composed of positive numbers. If $\mathrm{u}_{\mathrm{eq}}$ is supposed to be the equivalent control after system enters the sliding mode, then

$$
\begin{aligned}
\dot{S} & =C \dot{X}_{e} \\
& =C\left(\dot{X}^{\prime}-\dot{X}_{R}\right) \\
& =C\left(A^{\prime} X^{\prime}+B^{\prime} u_{e q}\right)-C\left[\begin{array}{lll}
\omega_{\mathrm{g} 0} & 0 & 0
\end{array}\right]^{T} \\
& =0
\end{aligned}
$$

Because the rank of matrix $\mathrm{CB}^{\prime}$ is full,

$$
\mathrm{u}_{\mathrm{eq}}=\left[\mathrm{CB}^{\prime}\right]^{-1} \cdot\left(\mathrm{CX}_{\mathrm{R}}-\mathrm{CA}^{\prime} \mathrm{X}^{\prime}\right)
$$

In order to ensure that system state reaches the sliding mode surface within limited time $[6,7], \mathrm{U}$ is defined as

$$
\mathrm{U}=\mathrm{u}_{\mathrm{eq}}+\mathrm{u}_{\mathrm{VsS}}=\mathrm{KX}^{\prime}-\mathrm{f} \cdot \operatorname{sgn}(\mathrm{S})
$$

When system is on the switching surface, the system state equation is described as

$$
\dot{\mathrm{X}}^{\prime}=\mathrm{A}^{\prime} \mathrm{X}^{\prime}+\mathrm{B}^{\prime} \mathrm{K} \mathrm{X}^{\prime}=\left(\mathrm{A}^{\prime}+\mathrm{B}^{\prime} \mathrm{K}\right) \mathrm{X}^{\prime}
$$

If the state feedback gain matrix is designed as

$$
\mathrm{K}=-\left[\mathrm{CB}^{\prime}\right]^{-1} \mathrm{CA}^{\prime}
$$

then ideal control effect can be achieved and the value of parameters can be further determined.

2.3. Adaptive Mechanism. In actual control application, uncertain parameters of system and external gust wind disturbance are random variables [8]. As a parameter of the above controller, $\mathrm{Q}_{\mathrm{D}}$ satisfies

$$
\left|Q_{D}\right| \leq \bar{f}
$$

where $\bar{f}$ is the upper bound of $Q_{D}$ and is obtained with difficulty. Therefore, adaptive estimation for the upper bound of $Q_{D}$ is achieved through adaptive control method. If $\widehat{f}$ is estimated value of $\bar{f}$, the control law can be designed as

$$
\mathrm{U}(\mathrm{t})=\mathrm{KX} \mathrm{X}^{\prime}+\widehat{\mathrm{f}} \cdot \operatorname{sgn}(\mathrm{S}(\mathrm{t}))+\frac{\mathrm{CX}_{\mathrm{R}}}{\mathrm{CB}^{\prime}}
$$

where the adaptive law is expressed as

$$
\dot{\hat{\mathrm{f}}}=-\frac{1}{\mathrm{a}}\left|\mathrm{s}(\mathrm{t}) \mathrm{CB}^{\prime}\right|
$$

and variable $\mathrm{a}$ is the positive gain of adaptive term. The Lyapunov function $[9,10]$, which is defined in equation (32), is adopted to prove the controller design is stable.

$$
\mathrm{V}=\frac{1}{2} \mathrm{~S}^{2}+\frac{1}{2} \mathrm{af}(\mathrm{t})^{2}
$$




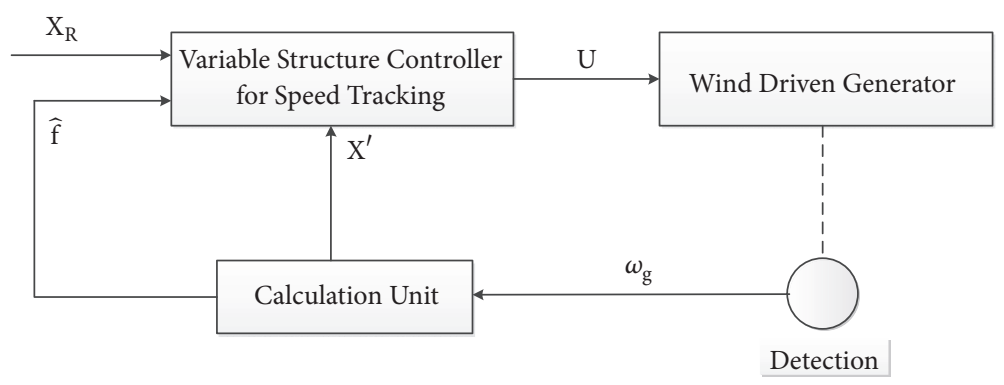

FIGURE 2: Control diagram of wind driven generator.

If $\widetilde{\mathrm{f}}(\mathrm{t})$ is defined as

$$
\tilde{\mathrm{f}}(\mathrm{t})=\overline{\mathrm{f}}-\widehat{\mathrm{f}}
$$

equation (34) can be obtained:

$$
\begin{aligned}
\dot{S} & =\mathrm{CX}_{\mathrm{e}}=\mathrm{C}\left(\dot{\mathrm{X}}^{\prime}-\dot{\mathrm{X}}_{\mathrm{R}}\right)=\mathrm{C}\left(\mathrm{A}^{\prime} \mathrm{X}^{\prime}+\mathrm{B}^{\prime} \mathrm{U}+\mathrm{B}^{\prime} \mathrm{Q}_{\mathrm{D}}\right. \\
& \left.-\dot{\mathrm{X}}_{\mathrm{R}}\right)=\mathrm{C}\left(\mathrm{A}^{\prime} \mathrm{X}^{\prime}+\mathrm{B}^{\prime} \mathrm{KX}^{\prime}+\mathrm{B}^{\prime} \widehat{\mathrm{f}} \cdot \operatorname{sgn}(\mathrm{S})+\mathrm{B}^{\prime} \mathrm{Q}_{\mathrm{D}}\right. \\
& \left.+\mathrm{B}^{\prime} \cdot \frac{\mathrm{C} \dot{X}_{\mathrm{R}}}{\mathrm{CB}^{\prime}}-\dot{\mathrm{X}}_{\mathrm{R}}\right)=\mathrm{CB}^{\prime}\left(\mathrm{Q}_{\mathrm{D}}+\widehat{\mathrm{f}} \cdot \operatorname{sgn}(\mathrm{S})\right)
\end{aligned}
$$

Because

$$
\begin{aligned}
\mathrm{a} \cdot \tilde{\mathrm{f}} \cdot \dot{\overrightarrow{\mathrm{f}}} & =\mathrm{a} \cdot \tilde{\mathrm{f}} \cdot \frac{1}{\mathrm{a}} \cdot\left|S C B^{\prime}\right|=\widetilde{\mathrm{f}} \cdot\left|S C B^{\prime}\right| \\
& =\mathrm{CB}^{\prime}(\overline{\mathrm{f}}-\widehat{\mathrm{f}}) \cdot|\mathrm{S}|
\end{aligned}
$$

then equation (36) can be derived from equation (34) and equation (35):

$$
\begin{aligned}
\dot{\mathrm{V}} & =\mathrm{CB}^{\prime}\left(\mathrm{SQ}_{\mathrm{D}}+\widehat{\mathrm{f}} \cdot|\mathrm{S}|\right)+\mathrm{CB}^{\prime}(\overline{\mathrm{f}}-\widehat{\mathrm{f}}) \cdot|\mathrm{S}| \\
& =\mathrm{CB}^{\prime}\left(\mathrm{SQ}_{\mathrm{D}}+\overline{\mathrm{f}} \cdot|\mathrm{S}|\right) \leq 0
\end{aligned}
$$

Therefore, $\mathrm{S}$ converges to zero when $\mathrm{t}$ increases towards infinity, and, similarly, $\mathrm{X}^{\prime}$ converges to $\mathrm{X}_{\mathrm{R}}$ when $\mathrm{t}$ increases towards infinity.

Figure 2 shows the actual control diagram of the modeled wind driven generator where calculation unit mainly completes the state variable calculation and implements the adaptive estimation algorithm for the upper bound of $Q_{D}$.

In summary, the design procedure for the integral variable structure controller is described as follows.

Step 1. Dynamics model of wind power system is founded where the rotational torque of generator (denoted by $\mathrm{Q}_{\mathrm{E}}$ ) is control input, the gust wind disturbance (denoted by $\mathrm{W}_{\mathrm{I}}$ ) is disturbance input, the generator rotation speed (denoted by $\omega_{\mathrm{g}}$ ) is system output, and the state variable of system is composed of wind turbine rotation speed (denoted by $\omega_{t}$ ), generator rotation speed, and the integration item $\mathrm{K}_{\mathrm{S}} \int_{0}^{\mathrm{t}}\left(\omega_{\mathrm{t}}-\right.$ $\left.\omega_{\mathrm{g}}\right) \mathrm{dt}$.

Step 2. Based on the dynamics model of wind power system, a second order differential equation founded with the generator rotation speed is obtained through equivalent transformation.

Step 3. As shown in equation (20), the extended dynamics model of system is derived from the second order differential equation mentioned in Step 2 and the state variable is comprised by the generator rotation speed, the integration item, and the differential item of generator rotation speed.

Step 4. The switching function of variable structure control is designed where the state error variable (denoted by $\mathrm{X}_{\mathrm{e}}$ ) is introduced.

Step 5. The equivalent control input after system enters the sliding mode (denoted by $\mathrm{u}_{\mathrm{eq}}$ ) is obtained through derivations of switching function.

Step 6. Based on the principle of pole setting through state feedback, the actual control input (denoted by $\mathrm{U}$ ) is transformed from the equivalent control input.

Step 7. The rotational torque of generator is calculated by the iterative algorithm, which is expressed as

$$
\mathrm{Q}_{\mathrm{Et}}=\mathrm{Q}_{\mathrm{E}(\mathrm{t}-1)}+\dot{\mathrm{Q}}_{\mathrm{E}(\mathrm{t}-1)} \cdot \mathrm{T}
$$

where $\mathrm{t}$ denotes the sampling time, $\mathrm{t}=1,2,3, \cdots$, and $\mathrm{T}$ denotes the sampling period, $\mathrm{T}=1 \mathrm{~ms}$.

If the adaptive estimation algorithm for the upper bound of $\mathrm{Q}_{\mathrm{D}}$ is introduced, above procedure can be modified as follows

Steps $1 \sim 5$. Steps 1 5 are the same as above corresponding steps.

Step 6. As shown in equation (31), adaptive estimation algorithm for the upper bound of $\mathrm{Q}_{\mathrm{D}}$ is introduced into the control law design of $\mathrm{U}(\mathrm{t})$.

Step 7. Step 7 is also the same as above corresponding step.

\section{Simulation Research}

In order to verify the control effect of integral variable structure controller in speed tracking of wind driven generator, the wind power system with $600 \mathrm{kw}$ rated power is regarded as 


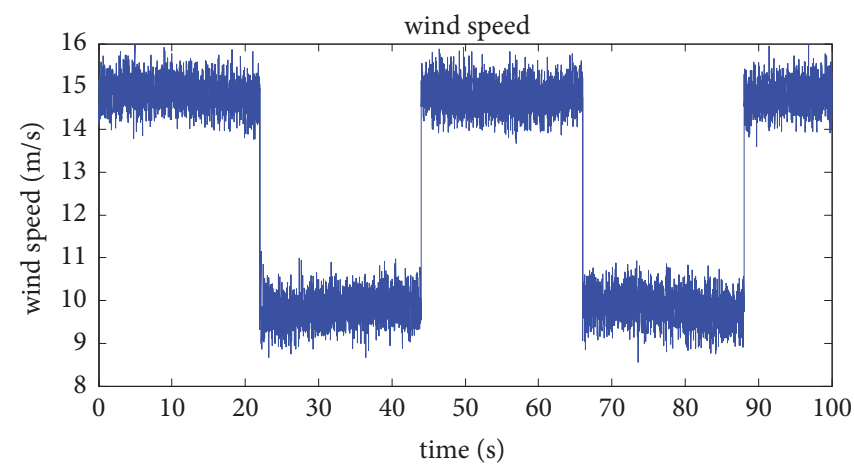

Figure 3: Wind speed signal.

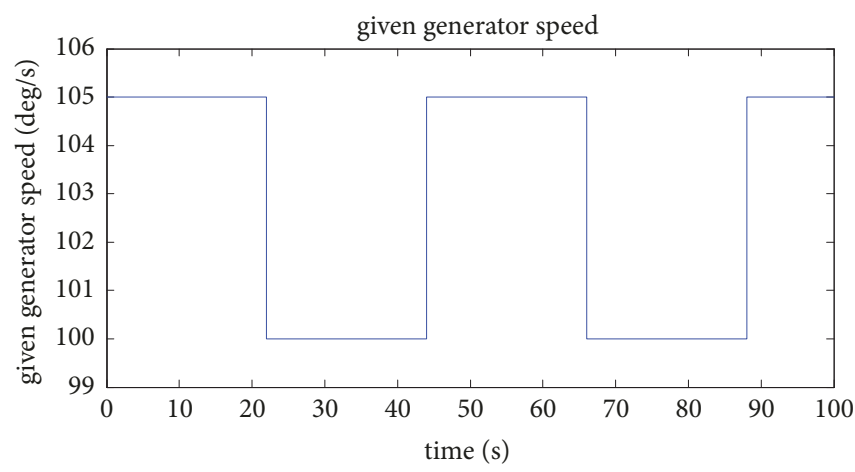

FIGURE 4: Given generator speed signal.

simulation object. Parameters of the wind power system are listed as follows:

$$
\begin{aligned}
\mathrm{J}_{\mathrm{T}} & =50000 \mathrm{~kg} \cdot \mathrm{m}^{2} \\
\mathrm{~J}_{\mathrm{G}} & =35 \mathrm{~kg} \cdot \mathrm{m}^{2} \\
\mathrm{~K}_{\mathrm{S}} & =100 \mathrm{~N} \cdot \mathrm{ms} / \mathrm{rad} \\
\mathrm{B}_{\mathrm{S}} & =1800 \mathrm{~N} \cdot \mathrm{ms} / \mathrm{rad} \\
\mathrm{R} & =25 \mathrm{~m} \\
\rho & =1.225 \mathrm{~kg} / \mathrm{m}^{3}
\end{aligned}
$$

Wind speed signal used in the simulation is shown in Figure 3. Given generator speed signal is square wave, as shown in Figure 4.

The wind speed signal in Figure 3 includes two types of wind, named as fundamental wind and random wind, respectively. The speed of fundamental wind is a constant and is determined by Weibull distribution parameters. The random wind indicates uncertainty of wind speed variation which can be simulated by random noise.

According to equation (5) and the following equation

$$
\omega_{\mathrm{g}}=\mathrm{n} \cdot \omega_{\mathrm{t}}
$$

the given generator speed signal in Figure 4 is derived as

$$
\omega_{\mathrm{g}}=\frac{\mathrm{n} \lambda_{\mathrm{op}}}{\mathrm{R}} \cdot \mathrm{w}
$$

where the range of $\lambda_{\text {op }}$ is

$$
0.48 \leq \lambda_{\text {op }} \leq 0.68
$$

Considering system uncertainty and external gust wind disturbance, relating parameters are given as

$$
\begin{aligned}
\Delta \mathrm{a} & =0.9 \\
\Delta \mathrm{b} & =5.4 \\
\chi & =0.1
\end{aligned}
$$

When general Variable Structure Control (ab. VSC) is adopted, the curve of generator speed tracking is shown in Figure 5, and the error curve of generator speed tracking is shown in Figure 6.

Simulation curves in Figures 5 and 6 show that actual output of generator speed chatters frequently near the given speed value, and the steady error of generator speed tracking is not zero when general variable structure control is adopted for generator speed track tracking. Therefore, the performance of generator speed tracking is poor.

When adaptive Integral Variable Structure Control (ab. IVSC) shown in equation (30) is adopted, following parameters are selected through the pole configuration method.

$$
\begin{aligned}
K & =\left[\begin{array}{lll}
0 & -0.1995 & -1798.95
\end{array}\right] \\
a & =1000 \\
C & =\left[\begin{array}{lll}
1 & 0.03 & 1
\end{array}\right]
\end{aligned}
$$




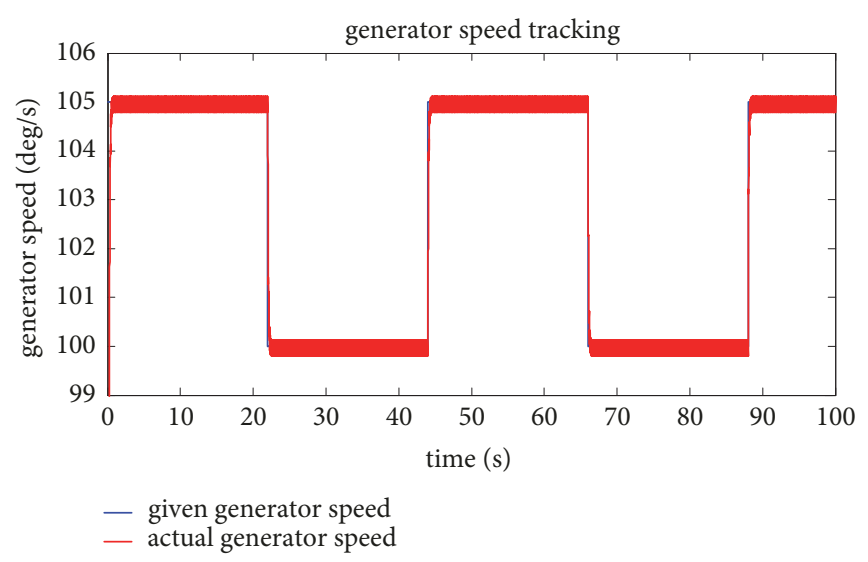

FIGURE 5: Generator speed tracking with general VSC.

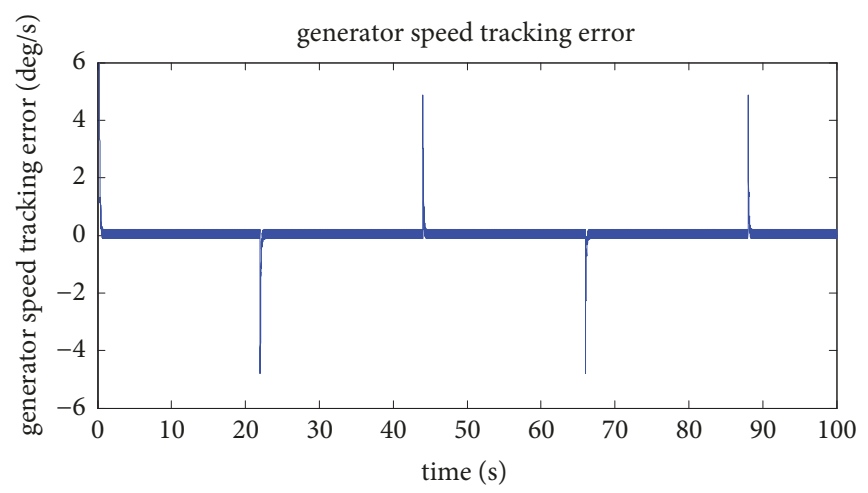

FIGURE 6: Generator speed tracking error with general VSC.

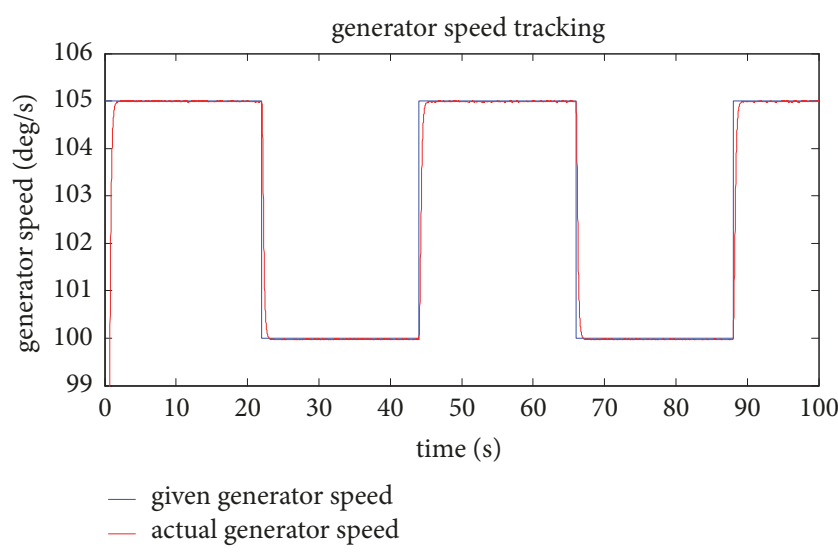

FIGURE 7: Generator speed tracking with IVSC.

At this point, the curve of generator speed tracking is shown in Figure 7, and the error curve of generator speed tracking is shown in Figure 8.

Simulation curves in Figures 7 and 8 show that actual output of generator speed is stable without frequent chattering near the given speed value, and the steady error of generator speed tracking is zero when adaptive variable

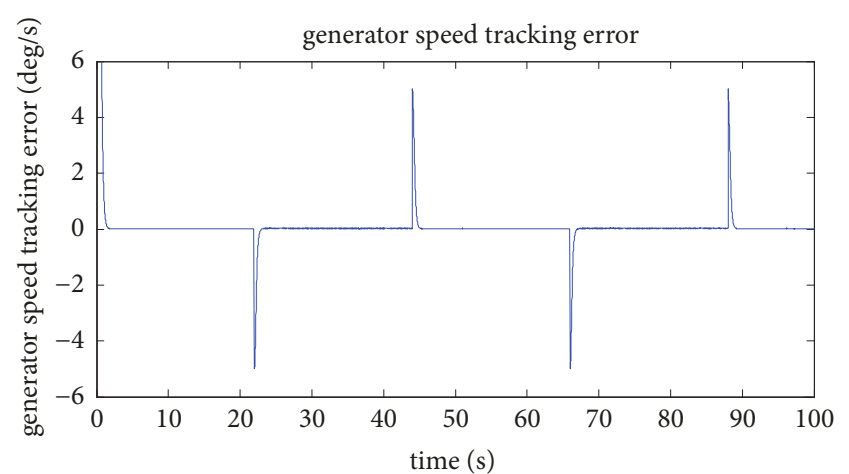

FIGURE 8: Generator speed tracking error with IVSC.

structure control is adopted for generator speed tracking. Tracking control with better precision is achieved.

\section{Conclusions}

The problem in system design, caused by dynamics model uncertainty of wind power system, can be solved through the integral variable structure controller applied to achieve speed tracking of wind driven generator and adaptive estimation method adopted for optimization of variable structure 
controller parameters. Frequent chattering phenomenon in actual output of generator speed is restrained effectively. The steady error of speed tracking, caused by gust wind disturbance, is eliminated and the tracking performance is significantly improved. Therefore, the adaptive integral variable structure control is a practical and effective method used to achieve accurate speed tracking of wind driven generator.

\section{Data Availability}

The data used to support the findings of this study are available from the corresponding author upon request.

\section{Conflicts of Interest}

The authors declare that they have no conflicts of interest.

\section{Acknowledgments}

Portions of this work were performed under the projects supported by National Natural Science Foundation of China (Grant Number 61540004), Natural Science Foundation of Inner Mongolia, China (Grant Number 2016MS0607), and Science Research Foundation of Inner Mongolia University of Technology (Grant Number X201520).

\section{References}

[1] X. Zhang, Power Tracking and Control in Micro-distributed Wind Power System, Zhejiang University, 2014.

[2] D. Zhang, Y. J. Wei, Z. Y. Hou et al., "Maximum power point tracking of doubly fed wind power generation system based on direct power control," Power Electronics, vol. 50, no. 1, pp. 41-44, 2016.

[3] D. V. N. Ananth and G. V. Nagesh Kumar, "Tip speed ratio based MPPT algorithm and improved field oriented control for extracting optimal real power and independent reactive power control for grid connected doubly fed induction generator," International Journal of Electrical and Computer Engineering, vol. 6, no. 3, pp. 1319-1331, 2016.

[4] J. Liu, H. Meng, and Y. Hu, "Efficiency optimization of optimum torque maximum power point tracking based on gradient approximation for wind turbine generator system," Proceedings of the Chinese Society of Electrical Engineering, vol. 35, no. 10, pp. 2367-2374, 2015.

[5] G. V. Lakhekar and L. M. Waghmare, Advances and Applications in Sliding Mode Control systems, Springer, London, UK, 2015.

[6] R. Munje, B. Patre, and A. Tiwari, Sliding Mode Control, Springer, London, UK, 2018.

[7] C. Edwards and Y. B. Shtessel, "Adaptive continuous higher order sliding mode control," Automatica, vol. 65, pp. 183-190, 2016.

[8] A. Tohidi, H. Hajieghrary, and M. A. Hsieh, "Adaptive disturbance rejection control scheme for DFIG-based wind turbine: theory and experiments," IEEE Transactions on Industry Applications, vol. 52, no. 3, pp. 2006-2015, 2016.

[9] T. Sanchez, J. A. Moreno, and F. A. Ortiz-Ricardez, "Construction of a smooth lyapunov function for the robust and exact second-order differentiator," Mathematical Problems in Engineering, vol. 2016, Article ID 3740834, 12 pages, 2016.

[10] T. Leth, C. Sloth, and R. Wisniewski, "Lyapunov function synthesis - algorithm and software," in Proceedings of the 2016 IEEE Conference on Computer Aided Control System Design, CACSD 2016, pp. 641-647, Argentina, September 2016. 


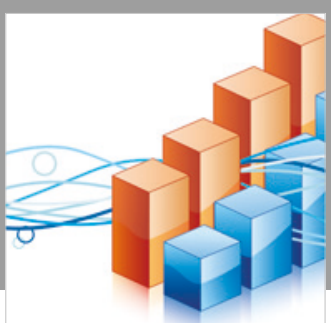

Advances in

Operations Research

\section{-n-m}
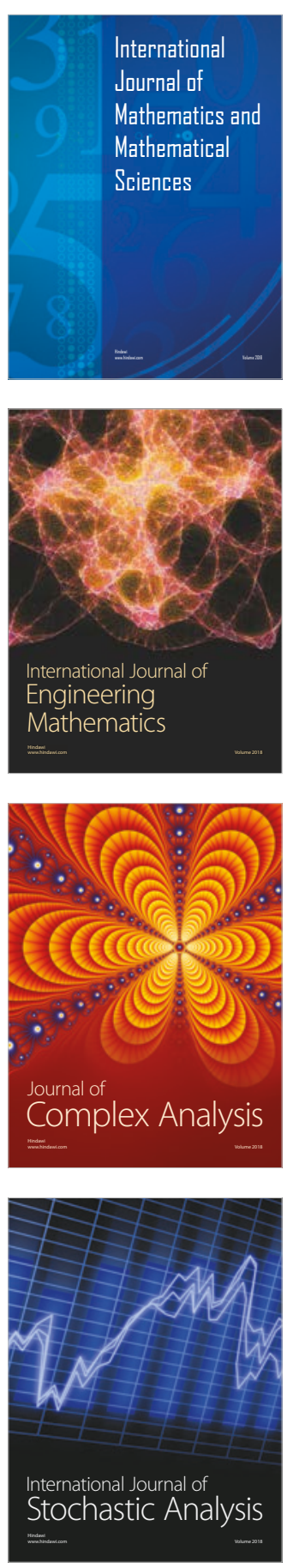
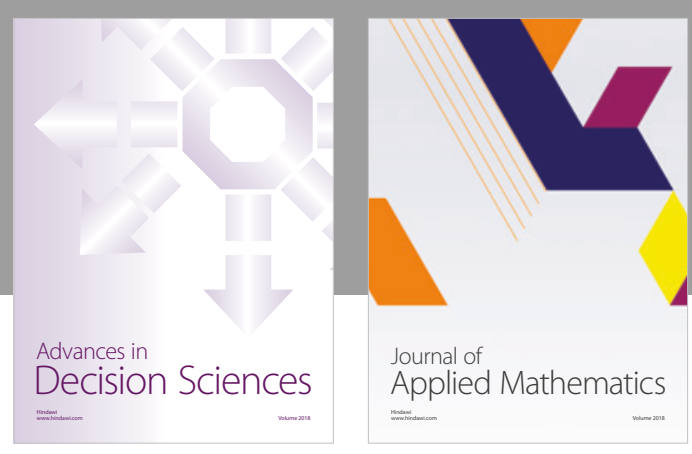

Journal of

Applied Mathematics
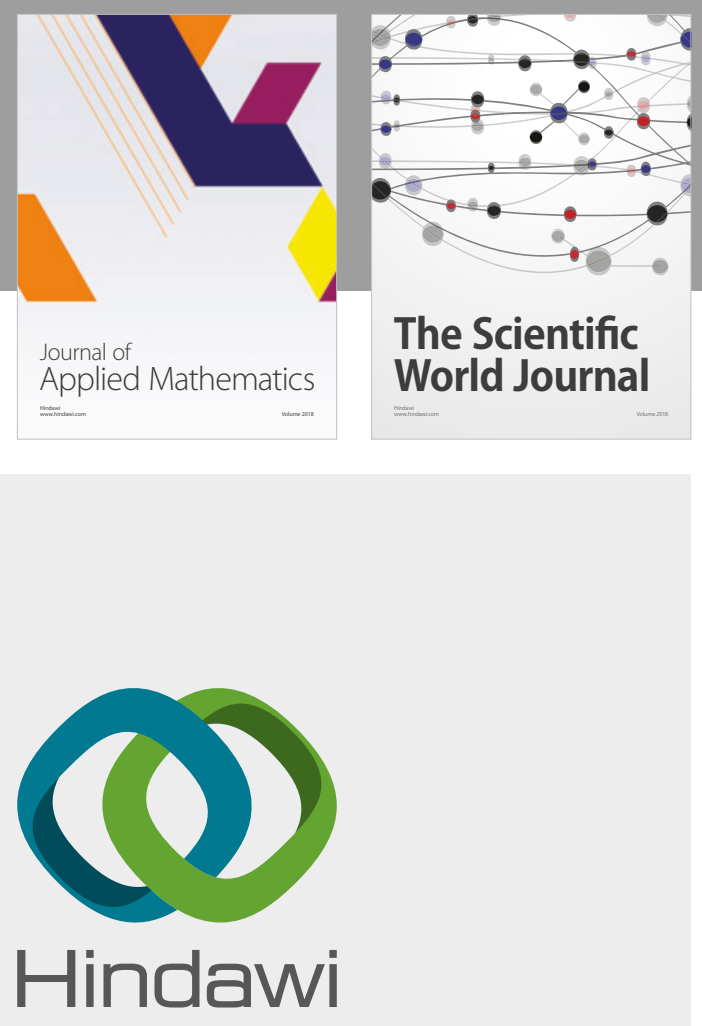

Submit your manuscripts at

www.hindawi.com

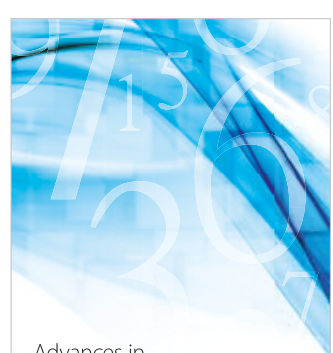

Advances in
Numerical Analysis
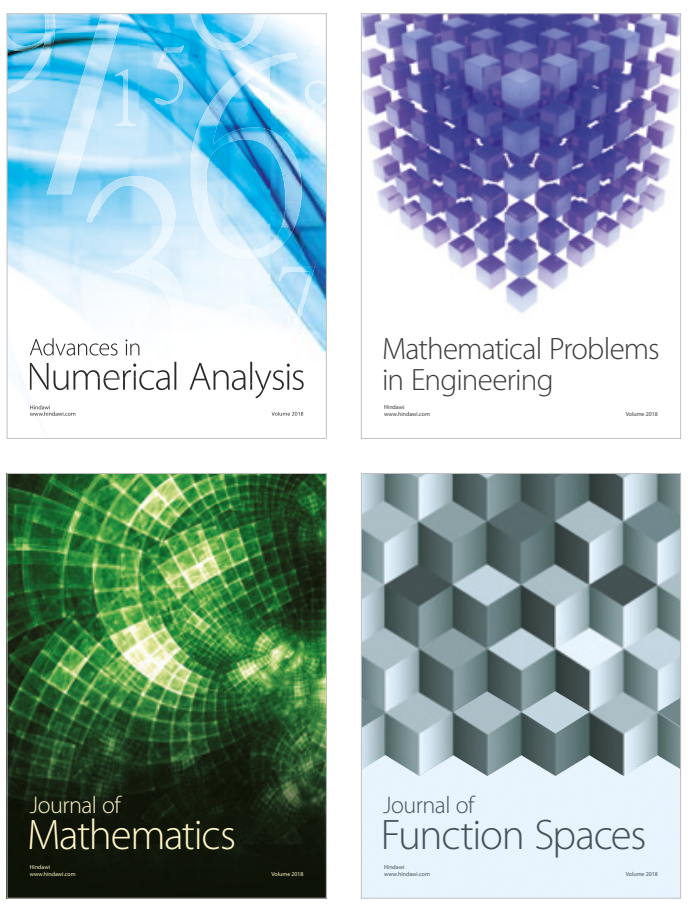

Mathematical Problems in Engineering

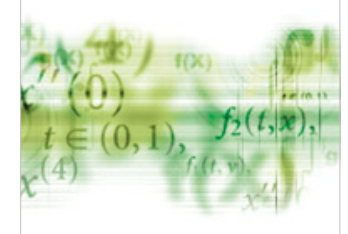

International Journal of

Differential Equations

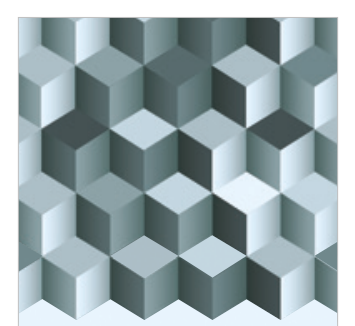

Journal of

Function Spaces

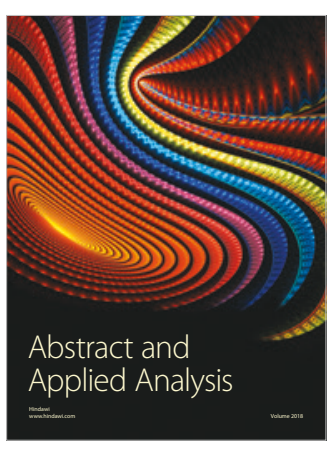

The Scientific

World Journal

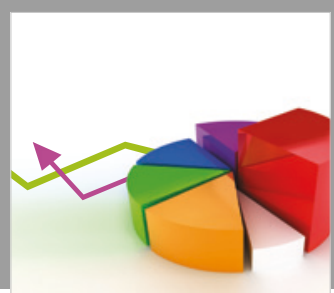

Journal of

Probability and Statistics
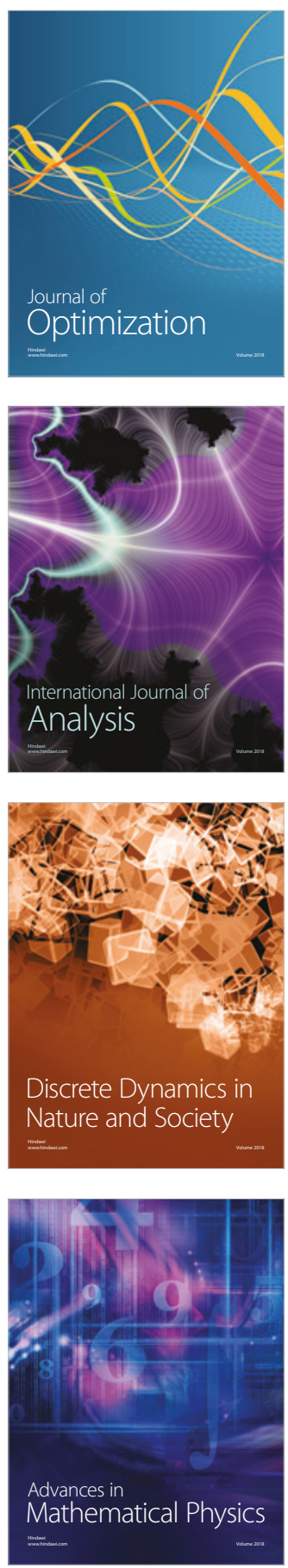